\title{
CHEMICAL ANALYSES OF GRASSES $x^{\prime}$
}

By Joseph H. Axtmayer, G. Rivera Hermanaez and D. H. Cook with the technical assistance of José $A$. Goyco and $M$. C. de Ferndindez2

From the Department of Chemistry of the School of Tropical Medicine, San

Juan, Puerto Rico and the Department of Chemistry of the Agricultural Experiment Station, Río Piedras, Puerto Rico.

The object of this study. was to find through the medium of a systematic survey, grasses which would be worthwhile a trial in our studies of the nutritive values of forage crops of Puerto Rico. Although the findings from a chemical analysis of a grass do not yield all the data necessary for judging its nutritive value, nevertheless, some light is shed upon its possibilities. Grasses of good nutiritive qualities with root systems capable of reducing soil erosion would be of double value to the agricultural economies of the Island.

Puerto Rico imports large quantities of mixed feed concentrates used by the dairy industry. Even so, the milk production is insufficient to meet the needs of the inhabitants of the Island, were each individual to receive the daily amount considered adequate by our present knowledge of optimum nutritional requirements. It is also expensive, considering the income of the lower class of people. We see no reason why uncultivated regions could not be used to produce crops which could be used as forage, not only for grazing, but for cutting and mixing with other crops in the preparation of concentrates.

\section{MATERIALS}

All the grasses analyzed had been cut during the blooming stage with the exception of sample 64, same grass as sample 63,

1 Cooperative project between the School of Tropical Medicine and the Agricultural Experiment Station.

2 Mr. G. L. Crawford, Chief, Soil Conservation Service in Puerto Rico, and Dr. H. W. Alberts cooperated by furnishing samples of varieties and species and also valuable agronomic data. 
which was cut during the after-blooming stage. Our reason for collecting the grasses for analysis during the blooming stage was to obtain comparable samples. Although it is known that an actively growing unmature grass, contains more protein and more total digestible nutrients than the more mature plants, the flowering stage was selected for the sake of uniformity.

\section{METHODS OF ANALYSIS}

The samples were brought to the laboratory as soon as eut. They were then cleaned, cut into smaller sizes, weighed and placed in a large horizontal flow, forced-air oven for the moisture determinations. When dry, they were ground in a Wiley mill, and the powder stored in air-tight bottles for the determinations of the other constituents. The analyses were performed according to the methods of the Official Agxicultural.Chemists. All analyses for a given constituent were performed in duplicate.

\section{DISCUSSION}

The analyses of the grasses as reported on the dry basis show that some are quite rich in total crude protein, and would yield a hay of some nutritional value. Those yielding a percentage of protein above ten (10) could be used for this purpose.

They are low in ether-soluble extract (fat) and high in crude fiber, as is to be expected. The nitrogen-free extract (carbohydrates) averages around 45-50\% and is a good souxce of energy.

The most favorable ratio of calcium to phosphorus for growth and bone formation is between 2 and 1 and 1 and 2 . With the amount of ultraviolet radiation available throughout the year in the sunshine of Puerto Rico, an abundance of vitamin $\mathrm{D}$ for the mobilization of the calcium and phosphorus is assured. The calcium and phosphorus ratios of the grasses studied are all narrow and within the limits of profitable utilization.

Abundance of all the other vitamins is also a certainty in the fresh grasses but may be reduced when these are dried.

Nutritional studies which have been planned include some of these grasses, to be used either fresh, as cut, or as hay, in the experimental rations. The formulation of a cheap ration, nutritionally adequate, consisting of crops grown in Puerto Rico would be of great help in the production of cheap milk which is of such great importance in human dietaries. 


\section{SUMMARX}

Chemical analyses of eighty-three grasses, calculated on the wet and dry basis, are reported. Their composition is discussed from a nutritional point of view.

Scientific, Fnglish and Spanish common names of the grasses are also given. 